Pacific Journal of Mathematics

SEQUENCES OF COVERINGS 


\title{
SEQUENCES OF COVERINGS
}

\author{
A. H. STONE
}

1. Introduction. The metrisable spaces $S$ for which $S^{\prime}$ (the set of limit points of $S$ ) is compact, can be characterized as those uniformisable spaces for which the finest uniformity (compatible with the topology) is metrisable (see [5], [1], where further characterizations are given). B. T. Levshenko has shown [4] that they also coincide with the regular spaces in which every point-finite covering ${ }^{1}$ can be refined by one of a fixed sequence of point-finite coverings, and that "point-finite" can be replaced throughout by "star-finite" or "locally finite". We shall extend these results (Theorem 2) and obtain an analogue for uniform spaces (Theorem 3). The proofs depend on a criterion for metrisability (Theorem 1) which may be of independent interest since, though not really new in content, it is particularly simple in form.

Notation. If $\mathscr{U}$ is a covering of a space $S$, and $A \subset S$, the star $\operatorname{St}(A, \mathscr{U})$ of $A$ in $\mathscr{U}$ is $\bigcup\{U \mid U \in \mathscr{U}, A \cap U \neq \phi\}$. When $A$ is a 1-point set $(x)$, we abbreviate $S t((x), \mathscr{C})$ to $S t(x, \mathscr{U})$. The covering by the sets $S t(U, \mathscr{U}), U \in \mathscr{U}$, is denoted by $S t(\mathscr{U})$. A covering $\mathscr{U}$ will be called "almost discrete" if only finitely many pairs $U, V$ of sets of $\mathscr{U}$ intersect; such a covering is clearly star-finite (in fact star-bounded) and so locally finite.

\section{Metrisation criterion.}

THEOREM 1. A necessary and sufficient condition that a $T_{0}$ space $S$ be metrisable is that $S$ have a sequence of coverings $\mathscr{U}_{n}, n=1,2, \cdots$, such that, for each $x \in S$, the stars $S t\left(G, \mathscr{U}_{n}\right)$ of the open sets $G \ni x$ form a basis for the neighborhoods of $x$.

The condition is trivially necessary. To prove it sufficient, we observe first that $S$ is developable-i.e., the stars $S t\left(x, \mathscr{Q}_{n}\right)$ form a basis for the neighborhoods of each $x \in S$. It follows that $S$ is $T_{1}$; for if $x, y$ are distinct points of $S$, one of them, say $x$, has a neighborhood $S t\left(x, \mathscr{U}_{n}\right)$ not containing $y$, and then $S t\left(y, \mathscr{U}_{n}\right)$ does not contain $x$. We next show that $S$ is collectionwise normal (see [2]). We may assume that $\mathscr{U}_{n+1}$ refines $\mathscr{U}_{n}$ (by replacing each $\mathscr{U}_{n}$ by the "intersection" of the coverings $\left.\mathscr{U}_{1}, \cdots, \mathscr{U}_{n}\right)$. Let $A_{\lambda}(\lambda \in \Lambda)$ be a discrete collection of closed subsets of $S$, and for each $n$ and $\lambda$ put

$$
H_{n \lambda}=\bigcup\left\{U \mid U \in \mathscr{U}_{n}, \operatorname{St}\left(U, \mathscr{U}_{n}\right) \text { meets } A_{\lambda} \text { but not } A_{\mu} \text { if } \mu \neq \lambda\right\} \text {, }
$$

Received June 8, 1959.

1 Throughout this paper, "covering" means "open covering." 
Let $P_{n \lambda}=\bigcup\left\{H_{m \mu} \mid m \leqq n, \mu \neq \lambda\right\}, K_{n \lambda}=H_{n \lambda}-\bar{P}_{n \lambda}, H_{\lambda}=\bigcup\left\{H_{n \lambda} \mid n=1,2, \cdots\right\}$, $K_{\lambda}=\bigcup\left\{K_{n \lambda} \mid n=1,2, \cdots\right\}$; these sets are all open. It is easy to verify that $K_{\lambda} \cap K_{\mu}=\phi$ if $\lambda \neq \mu$, that $A_{\lambda} \subset H_{\lambda}$, and that $A_{\lambda} \cap \bar{P}_{n \lambda}=\phi$; hence $A_{\lambda} \subset K_{\lambda}$ where the sets $K_{\lambda}$ are disjoint and open, as required.

As Bing has proved [2, Th. 10] that every developable collectionwise normal $T_{1}$ space is metrisable, the theorem follows. Alternatively Theorem 1 could be deduced from a general theorem of Nagata [6], or from a theorem of F. B. Jones [3].

3. THEOREM 2. The following statements about a regular $T_{1}$ space $S$ are equivalent:

(1) $S$ is metrisable and $S^{\prime}$ is compact,

(2) $S$ has a sequence of coverings $\mathscr{G}_{n}(n=1,2, \cdots)$ such that each finite covering of $S$ is refined by some $\mathscr{G}_{n}$,

(3) S has a sequence of almost discrete coverings $\mathscr{G}_{n}(n=1,2, \cdots)$ such that each covering of $S$ is refined by some $\mathscr{G}_{n}$.

The implication $(3) \rightarrow(2)$ is trivial. To prove $(2) \rightarrow(1)$, we first show that, assuming (2), $S$ is metrisable. Given $x \in U$ where $U$ is open in $S$, there is an open set $V$ such that $x \in V$ and $\bar{V} \subset U$. The finite covering $\mathscr{F}=\{V, U-(x), S-\bar{V}\}$ of $S$ has a refinement $\mathscr{G}_{n}$, and $x \in$ some $G^{0} \in \mathscr{G}_{n}$; then $G^{0} \subset V$, the only set of $\mathscr{F}$ which contains $x$. If $G^{1} \in \mathscr{G}_{n}$ and meets $G^{0}$, it follows that $G^{1} \subset V \cup(U-(x))=U$. Thus $S t\left(G^{0}, \mathscr{G}_{n}\right) \subset U$, so Theorem 1 applies and $S$ is metrisable. Let $\rho$ be a metric for $S$; we construct another, $\sigma$, for which each $\mathscr{G}_{n}$ is uniform. We do this by successively constructing coverings $\mathscr{U}_{1}, \mathscr{U}_{2}, \cdots$, such that $\operatorname{St}\left(\mathscr{U}_{n+1}\right)$ refines $\mathscr{U}_{n}, \mathscr{U}_{n}$ refines $\mathscr{G}_{n}$, and $\mathscr{U}_{n}$ consists of sets of $\rho$-diameters $<1 / n$. By $[7$, p. 51] there is a corresponding pseudo-metric $\sigma$ for which each $\mathscr{Z}_{n}$, and so each $\mathscr{G}_{n}$, is uniform; and as $\sigma(x, y)=0$ implies $\rho(x, y)=0$ here, $\sigma$ is a metric. Condition (2) shows that every finite covering of $S$ is uniform in the metric $\sigma$; it follows ([5]; see also [1, Th. $1,(4) \rightarrow(3)]$ that $S^{\prime}$ is compact (and every covering of $S$ is uniform).

Finally, (1) $\rightarrow(3)$ by the argument in [4], which we sketch for completeness. For each $n=1,2, \cdots$, cover $S^{\prime}$ by a finite system of open sets $G_{n i}\left(i=1,2, \cdots, k_{n}\right)$ of diameters $<1 / n$, all meeting $S^{\prime}$, and adjoin the 1-point sets $(x)$ for each $x \in S-\bigcup\left\{G_{n i} \mid i=1, \cdots, k_{n}\right\}$ to produce an almost discrete covering $\mathscr{G}_{n}$ of $S$. It is easy to see that every covering $\mathscr{U}$ of $S$ is refined by $\mathscr{G}_{n}$ when $n$ is large enough.

REMARK. To require that $S$ be separable, in (1), would be equivalent to requiring that the coverings $\mathscr{G}_{n}$ be countable, in (2) and (3).

THEOREM 3. The following statements about a completely regular $T_{1}$ space $S$ are equivalent:

(1) $S$ is metrisable, 
(2) S has a uniformity in which every finite uniform covering is refined by some member of a fixed sequence of (not necessarily uniform) coverings $\mathscr{G}_{n}$ of $S$,

(3) $S$ has a uniformity in which every uniform covering is refined by some member of a fixed sequence of locally finite uniform coverings $\mathscr{G}_{n}$ of $S$.

To prove $(1) \rightarrow(3)$, we use the fact that $S$ is paracompact to take $\mathscr{G}_{n}=$ a locally finite refinement of the covering of $S$ by "spheres" of radius $1 / n$. As (3) $\rightarrow(2)$ trivially, it remains to deduce (1) from (2). Given a neighborhood $N$ of $x \in S$, there exists a uniform covering $\mathscr{U}$ such that $S t(x, \mathscr{C}) \subset N$, and there exist uniform coverings $\mathscr{V}, \mathscr{W}$ such that $S t(\mathscr{Y})$ refines $\mathscr{U}$ and $S t(\mathscr{W})$ refines $\mathscr{Y}$. Let $x \in W_{0} \in \mathscr{W}$ and $S t\left(W_{0}, \mathscr{W}\right) \subset V \in \mathscr{Y} . \quad$ Write $\quad X=S t\left(W_{0}, \mathscr{W}\right), \quad Y=\bigcup\{W \mid W \in \mathscr{W}$, $x \notin W, W$ meets $V\}, Z=\bigcup\{W \mid W \in \mathscr{W}, W \cap V=\phi\}$. Then $\mathscr{F}=$ $\{X, Y, Z\}$, being refined by $\mathscr{W}$, is a uniform covering of $S$. Some $\mathscr{G}_{n}$ refines $\mathscr{F}$; say $x \in G^{0} \in \mathscr{G}_{n}$. Because $X \cap Z=\phi$, it follows by an argument similar to one used in the proof of Theorem 2 that $\operatorname{St}\left(G^{0}, \mathscr{G}_{n}\right) \subset$ $X \cup Y \subset S t(V, \mathscr{Y}) \subset S t(V, \mathscr{Y}) \subset S t(x, \mathscr{U}) \subset N$; hence $S$ is metrisable, by Theorem 1.

REMARK. The uniformities in (2) and (3) of Theorem 3 will be different in general; that in (3) will be metrisable, while that in (2) need not be. By Theorem 2, not every uniformity on $S$ can arise in (2) or (3) (unless $S^{\prime}$ is compact), but I have not found any satisfactory description of those which do.

\section{REFERENCES}

1. M. Atsuji, Uniform continuity of continuous functions of metric spaces, Pacific J. Math. 8 (1958), 11-16.

2. R. H. Bing, Metrization of topological spaces, Canadian J. Math. 3 (1951), 175-186.

3. F. Burton Jones, R. L. Moore's Axiom 1' and metrisation, Proc. Amer. Math. Soc. 9 (1958), 487.

4. B. T. Levshenko, On the concept of compactness and point-finite coverings, Mat. Sbornik. 42(84) (1957), 479-484.

5. J. Nagata, On the uniform topology of bicompactifications, J. Inst. Pol. Osaka City Univ 1 (1950), 28-38.

6. J. Nagata, A contribution to the theory of metrisation, ibid. 8 (1957), 185-192.

7. J. W. Tukey, Convergence and uniformity in topology, Princeton 1940.

UNIVERSITY OF MANCHESTER,

MANCHESTER, ENGLAND 



\section{PACIFIC JOURNAL OF MATHEMATICS}

\section{EDITORS}

David Gilbarg

Stanford University

Stanford, California

F. H. Brownell

University of Washington

Seattle 5, Washington
A. L. Whiteman

University of Southern Californıa Los Angeles 7, California

L. J. PaIge

University of California

Los Angeles 24, California

\section{ASSOCIATE EDITORS}
E. F. BECKENBACH
T. M. CHERRY
D. DERRY

E. HEWITT
A. HORN
L. NACHBIN
M. OHTSUKA

H. L. ROYDEN

M. M. SCHIFFER
E. SPANIER

E. G. STRAUS

F. WOLF

\section{SUPPORTING INSTITUTIONS}

\author{
UNIVERSITY OF BRITISH COLUMBIA \\ CALIFORNIA INSTITUTE OF TECHNOLOGY \\ UNIVERSITY OF CALIFORNIA \\ MONTANA STATE UNIVERSITY \\ UNIVERSITY OF NEVADA \\ NEW MEXICO STATE UNIVERSITY \\ OREGON STATE COLLEGE \\ UNIVERSITY OF OREGON \\ OSAKA UNIVERSITY \\ UNIVERSITY OF SOUTHERN CALIFORNIA
}

\author{
STANFORD UNIVERSITY \\ UNIVERSITY OF TOKYO \\ UNIVERSITY OF UTAH \\ WASHINGTON STATE COLLEGE \\ UNIVERSITY OF WASHINGTON \\ AMERICAN MATHEMATICAL SOCIETY \\ CALIFORNIA RESEARCH CORPORATION \\ HUGHES AIRCRAFT COMPANY \\ SPACE TECHNOLOGY LABORATORIES \\ NAVAL ORDNANCE TEST STATION
}

Mathematical papers intended for publication in the Pacific Journal of Mathematics should be typewritten (double spaced), and the author should keep a complete copy. Manuscripts may be sent to any one of the four editors. All other communications to the editors should be addressed to the managing editor, L. J. Paige at the University of California, Los Angeles 24, California.

50 reprints per author of each article are furnished free of charge; additional copies may be obtained at cost in multiples of 50 .

The Pacific Journal of Mathematics is published quarterly, in March, June, September, and December. The price per volume (4 numbers) is $\$ 12.00$; single issues, $\$ 3.50$. Back numbers are available. Special price to individual faculty members of supporting institutions and to individual members of the American Mathematical Society: $\$ 4.00$ per volume; single issues, $\$ 1.25$.

Subscriptions, orders for back numbers, and changes of address should be sent to Pacific Journal of Mathematics, 2120 Oxford Street, Berkeley 4, California.

Printed at Kokusai Bunken Insatsusha (International Academic Printing Co., Ltd.), No. 6, 2-chome, Fujimi-cho, Chiyoda-ku, Tokyo, Japan.

PUBLISHED BY PACIFIC JOURNAL OF MATHEMATICS, A NON-PROFIT CORPORATION

The Supporting Institutions listed above contribute to the cost of publication of this Journal, but they are not owners or publishers and have no responsibility for its content or policies. 


\section{Pacific Journal of Mathematics}

\section{Vol. 10, No. $2 \quad$ October, 1960}

Maynard G. Arsove, The Paley-Wiener theorem in metric linear spaces ........

Robert (Yisrael) John Aumann, Acceptable points in games of perfect

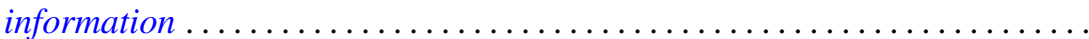

A. V. Balakrishnan, Fractional powers of closed operators and the semigroups generated by them ... . . . . . . . . . . . . . . . . . . . . . . . . . . . . 419

Dallas O. Banks, Bounds for the eigenvalues of some vibrating systems . . . . . 439

Billy Joe Boyer, On the summability of derived Fourier series . . . . . . . . . . . 475

Robert Breusch, An elementary proof of the prime number theorem with

remainder term ...................................

Edward David Callender, Jr., Hölder continuity of $n$-dimensional

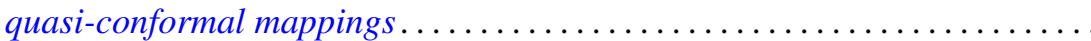

L. Carlitz, Note on Alder's polynomials ......................... 517

P. H. Doyle, III, Unions of cell pairs in $E^{3} \ldots \ldots \ldots \ldots \ldots \ldots \ldots \ldots \ldots \ldots \ldots \ldots . \ldots 21$

James Eells, Jr., A class of smooth bundles over a manifold . . . . . . . . . . . . 525

Shaul Foguel, Computations of the multiplicity function . . . . . . . . . . . . . . 539

James G. Glimm and Richard Vincent Kadison, Unitary operators in

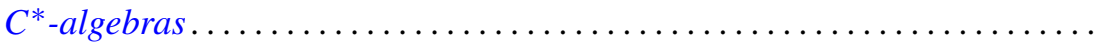

Hugh Gordon, Measure defined by abstract $L_{p}$ spaces . . . . . . . . . . . 557

Robert Clarke James, Separable conjugate spaces ....................

William Elliott Jenner, On non-associative algebras associated with bilinear forms

Harold H. Johnson, Terminating prolongation procedures

John W. Milnor and Edwin Spanier, Two remarks on fiber homotopy type .

Donald Alan Norton, A note on associativity . .

Ronald John Nunke, On the extensions of a torsion module.

Joseph J. Rotman, Mixed modules over valuations rings . . . . .

A. Sade, Théorie des systèmes demosiens de groupoï des . .

Wolfgang M. Schmidt, On normal numbers . .

661

Berthold Schweizer, Abe Sklar and Edward Oakley Thorp, The metrization of

statistical metric spaces

John P. Shanahan, On uniqueness questions for hyperbolic differential

equations

A. H. Stone, Sequences of coverings

Edward Oakley Thorp, Projections onto the subspace of compact operators

L. Bruce Treybig, Concerning certain locally peripherally separable spaces

Milo Wesley Weaver, On the commutativity of a correspondence and a

permutation

David Van Vranken Wend, On the zeros of solutions of some linear complex

differential equations. 